\title{
Environmental Impact of the Deregulation of Air-Transport: Evaluation of the Noise Level Around Secondary Airports
}

\author{
Andrea Benedetto*
}

Dept. Sciences of Civil Engineering, University Roma Tre, Via Vito Volterra, 62 - 00146 - Rome, Italy

\begin{abstract}
In the last decade, Low Cost Carriers (LCCs) have increased greatly, both in terms of number of flights and the number of passengers. This growth has occurred mainly in secondary airports, where air-transport was previously generally private and/or military. The large increase in LCCs coupled with the consolidated urbanization around the secondary airports has caused a substantial problem with environmental noise pollution. Currently, noise levels can be predicted using advanced numerical models that require many inputs to give reliable results, substantial computational resources, and high level know-how. For local communities and institutions, the implementation of such prediction models is often not possible, and, at the same time, air-transport companies are not always required by law to predict noise impact induced by changing flight operations.

Here, an effective low cost model for predicting noise levels around airports is presented. It is an advanced segmentation model that is easily implemented. The model has been calibrated using a case study referring to field noise measurements and predictions using consolidated models, such as INM (Integrated Noise Model, USA) and TNIP (Transparent Noise Information Package, Australia). The results demonstrate good reliability, both in single event simulations and noise contour predictions. Finally, the model has been applied to the planning of the third airport in Rome.
\end{abstract}

\section{INTRODUCTION}

In the last decade, beginning in the USA and Australia, and arising later in "Old-Europe", Low Cost Carriers increased greatly both in terms of the number of flights operated and the number of passengers and they have continued to increase all over the world. In 2005, the percentage of LCC increased to $26 \%$ of the total; in some countries, the LCCs are increasing more slowly, such as in Italy where that percentage in 2005 was about $8 \%$, while in other countries the number of LCCs are growing much more rapidly (over $40 \%)$.

The main strength of LCCs is the low cost for passengers, which is a consequence of the reduction and optimization of services provided for passengers, the optimization of the phases of ticketing, check-in, and flight assistance, and significant cost savings on aircraft maintenance. This is due to the specialization of the routes, and consequently, the limited number of aircraft models used.

In more detail, the most important points that make the LCC competitive are given below [1].

1. LLCs have an advantage in terms of ticket distribution as they do not always use travel agents who require a commission payment. Rather, they often use electronic ticketless systems.

2. LLCs generally have no class differentiation, high volume, no seat assignments, and no hot meals. This reduces the

*Address correspondence to this author at Dept. Sciences of Civil Engineering, University Roma Tre, Via Vito Volterra, 62 - 00146 - Rome, Italy; Tel: 0039.06.57333543; Fax: 0039.06.57333441; E-mail: benedet@uniroma3.it costs of cleaning cabins, the logistics of supplying the aircraft, and the time on the ground. Doganis estimated the reduction of the operation costs to be $6 \%$ [2].

3. LLCs tend to have high flight frequencies.

4. LLCs tend to have minimal delays.

5. LLCs charge low tariffs and maintain simple operations, usually lacking partnerships with other operators.

6. LLCs generally only use aircraft of a single type (i.e. Boeing 737 with four variations for Southwest) and maintain high levels of aircraft utilisation (over $11 \mathrm{~h} /$ day).

7. LLCs tend to favour direct short haul routes, averaging below $800 \mathrm{~km}$.

8. LLCs often use secondary airports with little congestion, leading to turn around times for aircraft as low as 15-20 $\min$.

9. LLCs maintain modest growth objectives (goals of $10 \%$ /year, not exceeding $15 \%$ ).

10. LLCs foster a feeling of team participation, offering competitive wages and profit sharing since 1973. This has resulted in high productivity.

These strategies are not acceptable for traditional or national airlines. In general, these companies have to fly over national and international courses, and need to have aircrafts of different types. The consequence is that the costs of maintenance (spare parts, technicians) are significant and any optimization or specialization is very difficult to implement.

Moreover, the standards of in-flight services are generally higher for national airlines, making the costs significantly higher than those incurred by LCCs. 
The distribution of financial costs for LCCs and traditional airlines is not very different; however, significant discrepancies can be seen considering the absolute costs [3].

In addition, team and staff wages are significantly different between traditional and low cost carriers. In some cases, the average wages of LCC employees are $50 \%$ of that of employees working for a traditional airline. The average wage in a LCC is between 30,000 and 40,000 USD/year, whereas in a traditional company, the average wage can be over 55,000 USD/year [3].

LCCs have attracted tourists with great success. Now the LCC demand is diversified, and this has produced an unexpected increase in the number of flights and routes.

A significant portion of the current LCC demand comes from business passengers [4, 5].

Passengers are generally interested in reducing the time and cost of transportation, and the procedures implemented by LCCs are very effective in this regard. Thus, the percentage of business passengers that currently choose low cost airlines is about $50 \%$.

However, the LCC system is exposed to many risks produced by the fierce and sometimes unfair competition among companies, and it is vulnerable to some external problems, such as the fluctuations in passenger demand, the instability of political situations, and the interests of airport management.

LCCs have been attracted to secondary airports originally used mostly or military and private flights. These airports are now sending flights all over the world.

Forsyth [6] found that, although secondary airports have economies of scale, there may be other factors that allow for lower costs. These factors include greater efficiency, lower quality services, and subsidies. However, economies of scale derived from high fixed costs may not exist, as some capacity costs may have dropped. As such, lower airport costs may be combined with revenues from other airport activities to enhance profitability. Non-airside (or concession) activities often provide the main part of an airport's revenues.

Initially, LCCs grew rapidly, although the growth was accompanied by fluctuations because of joint ventures, parcelling, and stripping. Now the growth seems to have levelled off to a steady state.

Beyond the critical economic and social aspects that characterize the growth of LCCs, one of the certainties is the significant increase in air-traffic at the secondary airports.

Generally, these airports are located close to or inside cities. In fact, the low traffic flow that characterizes the military or private demand is absolutely compatible with residential areas. More recently, high levels of low cost traffic have negatively impacted the environment in these areas, which makes the objectives of LCCs incompatible with the standards of a good quality of life.

The three main complications in these situations are as follows: (1) the accessibility of the airports from land, which includes the increase in traffic flow around the airport and road-rail congestion, (2) air pollution, and (3) noise pollution.
In this context, the consequence is frequently a strong opposition between the airport and LCC management and local communities and public institutions. The former are interested in transportation development, while the latter are worried about environmental impacts near the airports.

Of the complaints, noise pollution is the most common. Moreover, in spite of the increasing number of operations in the airport, no infrastructure rehabilitation or strengthening takes place, nor is an environmental impact assessment implemented. Furthermore, in the preliminary phases of flight operation planning, the companies are not asked to evaluate environmental impacts. The high costs of such evaluations (numerical simulations, on site measurements, etc.) may contribute to this as the available models for impact assessment (e.g. noise level prediction) require specialized technicians and non-negligible financial resources for implementation.

Here, an effective low cost model for predicting noise level around airports is presented: ELeNA (Evaluation of Level of Noise around Airport). It is an advanced segmentation model, which is easy to implement. It has been designed and developed at the University Roma Tre (DSIC).

\section{AIRCRAFT NOISE}

All around the world different metrics for the evaluation of noise around airports are used. The international scientific and institutional communities agree that airport noise has to be evaluated as discontinuous, which is different than road traffic noise or industrial noise. Table $\mathbf{1}$ summarizes the main indicators that are used around the world as airport noise metrics. Of course, analogies or analytical relationships among many of them do exist.

Generally, a variety of metrics may be used to assess the impacts of sound on a diverse spectrum of targets. Depending on the specific situation, appropriate metrics may include instantaneous levels, single event metrics, or cumulative metrics.

As shown in Table 1, the airport noise metrics are based on cumulative metrics. Cumulative metrics are most useful in characterizing the overall noise environment and are the primary metrics used in the analysis of community (exposed population) dose-response relationships.

Metrics used to characterize a single sound event include the instantaneous sound level as a function of time, the maximum sound level, the equivalent (average) level, and the Sound Exposure Level (SEL), which is a single number metric that incorporates both level and duration. The relationship between these metrics is illustrated in Fig. (1).

The single event maximum sound level metric, (Lmax), is simply the highest A-weighted sound level measured during an event. In the example illustrated in Fig. (1), Lmax is approximately $101 \mathrm{~dB}$. Although the instantaneous maximum value is the most easily understood descriptor for a noise event, it provides relatively little information alone. Specifically, it provides no information concerning either the duration of the event or the amount of sound energy. This metric is currently used for noise certification of small propellerdriven aircraft and to assess potential noise effects on animals. 
Table 1. Airport Noise Metrics Around the World

\begin{tabular}{|c|c|c|c|}
\hline Country & Metric & & Equation \\
\hline UK Switzerland & NNI & Noise and Number Index & $\mathrm{NNI}=\mathrm{L}_{\mathrm{pnmax}}+15 \log _{10} \mathrm{~N}-80$ \\
\hline USA & DNL & Day-night Average Sound Level & $\mathrm{DNL}=10 \log 1 / 24\left[15\left(10^{\mathrm{Ld} / 10}\right)+9\left(10^{(\mathrm{Ln}+10) / 10}\right)\right]$ \\
\hline California & CNEL & Community Noise Equivalent Level & $\mathrm{CNEL}=\mathrm{SENEL}+10 \log _{10}\left(\mathrm{~N}_{\mathrm{D}}+3 \mathrm{~N}_{\mathrm{E}}+10 \mathrm{~N}_{\mathrm{N}}\right)-49.4$ \\
\hline Canada & $\mathrm{NEF}$ & Noise Exposure Forecast & $\mathrm{NEF}=\mathrm{EPNL}+10 \log _{10}\left(\mathrm{~N}_{\mathrm{d}}+16.7 \mathrm{~N}_{\mathrm{n}}\right)-88$ \\
\hline Australia & ANEF & Australian Noise Exposure Forecast & $A N E F=E P N L+10 \log _{10}\left(N_{D}+4 N_{N}\right)-88$ \\
\hline Austria & $\mathrm{L}_{\mathrm{DN}}$ & Day-Night Average Noise Level & $\mathrm{DNL}=10 \log 1 / 24\left[15\left(10^{\mathrm{Ld} / 10}\right)+9\left(10^{(\mathrm{Ln}+10) / 10}\right)\right]$ \\
\hline Belgium & $\mathrm{L}_{\mathrm{DN}}$ & Day-Night Average Noise Level & $\mathrm{DNL}=10 \log 1 / 24\left[15\left(10^{\mathrm{Ld} / 10}\right)+9\left(10^{(\mathrm{Ln}+10) / 10}\right)\right]$ \\
\hline Denmark & $\mathrm{L}_{\mathrm{DN}}$ & Day-Night Average Noise Level & $\mathrm{DNL}=10 \log 1 / 24\left[15\left(10^{\mathrm{Ld} / 10}\right)+9\left(10^{(\mathrm{Ln}+10) / 10}\right)\right]$ \\
\hline France & $l_{\mathrm{p}}$ & Day-Night Average Noise Level & $l_{p}=10 \log \left(\sum g i 10^{0.1 L i}\right)-32$ \\
\hline Germany & $\mathrm{LA}_{\mathrm{eq}}$ & Day-Night Average Noise Level & $\mathrm{LAeq}=13.3 \log \left(1 / \mathrm{T} \sum \mathrm{g}_{\mathrm{i}} \mathrm{t}_{\mathrm{i}} 10 \mathrm{Li} / 13.3\right)$ \\
\hline Greece & $\mathrm{NEF}$ & Noise Exposure Forecast & $\mathrm{NEF}=10 \log _{10}\left[\Sigma_{\mathrm{i}} \Sigma_{\mathrm{j}} 10^{\mathrm{NEFij} / 10}\right]$ \\
\hline Ireland & NNI & Noise and Number Index & $\mathrm{NNI}=\mathrm{L}_{\mathrm{pn}}(\mathrm{av})+15 \log \mathrm{N}-80$ \\
\hline \multicolumn{3}{|c|}{ 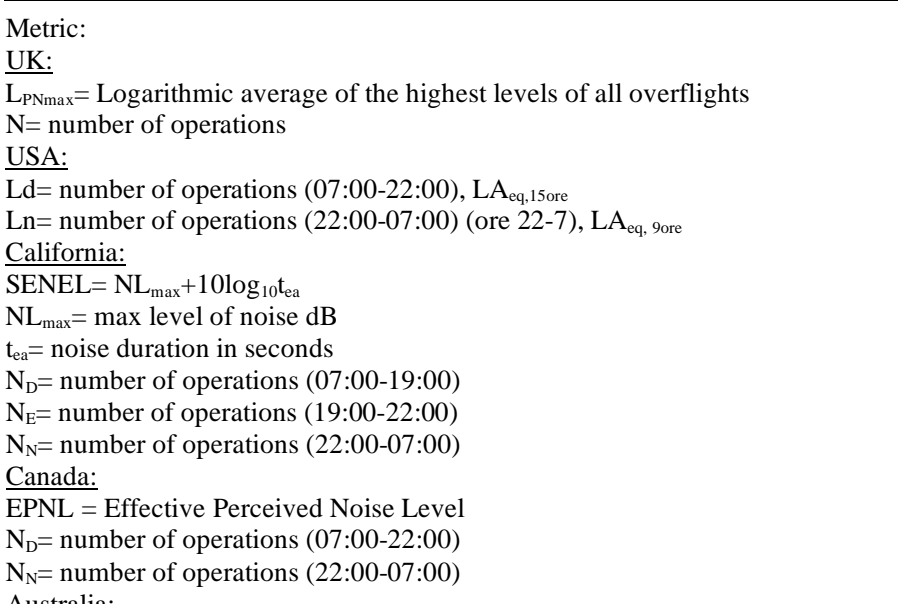 } & $\begin{array}{l}\mathrm{N}_{\mathrm{D}}=\text { number of operations }(07: 00-19: 00) \\
\mathrm{N}_{\mathrm{N}}=\text { number of operations }(19: 00-07: 00) \\
\text { France: } \\
\mathrm{L}_{\mathrm{i}}=\text { Noise from each operation in PNdBmax } \\
\mathrm{g}_{\mathrm{i}}=1 \text { for operations } 06: 00-22: 00 \text { and } 10 \text { for operations } 22: 00-06: 00 \\
\text { Germany: } \\
\mathrm{L}_{\mathrm{i}}=\text { noise level in } \mathrm{dB}(\mathrm{A}) \text { Smax } \\
\mathrm{T}=180 * 86400 \text { seconds } \\
\mathrm{t}_{\mathrm{i}}=10 \mathrm{~dB} \text { down time } \\
\left.\left.\mathrm{g}_{\mathrm{i}}=1 \text { (for } 06: 00-22: 00\right) \text { or } 5 \text { (for } 22: 00-06: 00\right) \\
\mathrm{Greece} \\
\mathrm{NEF}_{\mathrm{ij}}=\mathrm{L}_{\mathrm{EPNi}}+10 \log _{10}\left[\mathrm{nD} \mathrm{D}_{\mathrm{ij}}+16.7 \mathrm{nN} \mathrm{N}_{\mathrm{ij}}\right]-88 \\
\mathrm{nD} \mathrm{D}_{\mathrm{ij}}=\text { the number of day time flights }(0700-2200) \\
\mathrm{nN} \mathrm{N}_{\mathrm{ij}}=\text { the number of night time flights }(2200-0700) \\
\mathrm{Ireland}_{\text {: }} \\
\mathrm{L}_{\mathrm{pn}}(\mathrm{av})=\text { average noise level in PndBmax of all operations exceeding } \\
80 \text { PndBmax } \\
\mathrm{N}=\text { number of operations during period } 0600-2200\end{array}$ \\
\hline
\end{tabular}

Australia:

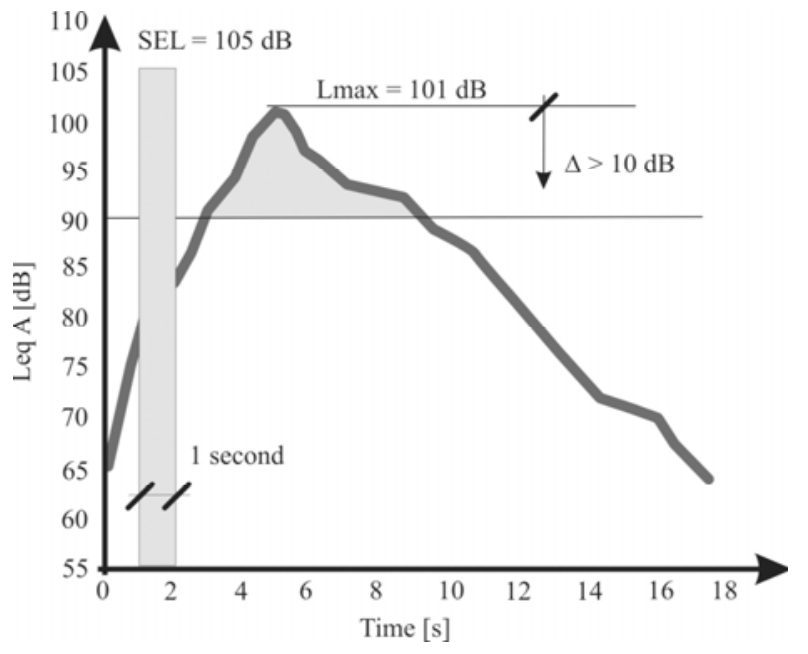

Fig. (1). Relationship between noise metrics: single event time history and $S E L$.

Subjective tests indicate that the human response to noise is a function not only of the maximum level, but also of the duration of the event and its variation with respect to time. This is taken into consideration in all the indicators shown in Table 1 by the evaluation of the Sound Exposure Level (SEL).

The SEL is a measure of the physical energy of the noise event that takes into account both intensity and duration. The $S E L$ is based on the integral of the weighted sound level during the period it is above a specified threshold (at least $10 \mathrm{~dB}$ below the maximum value measured during the noise event) with reference to a standardized duration of one second. Thus, the value of the $S E L$ is equal to the level of a constant sound with a duration of one second that would provide the same amount of sound energy as the event in question. It may be calculated using the equation for the equivalent level (Eq. 1) with the duration $(T)$ replaced by the referenced time (Tref) of 1 second.

$$
S E L=L_{A E}=10 \cdot \log \frac{1}{t_{0}} \int_{t 1}^{t_{1}} \frac{p_{A}^{2}(t)}{p_{0}} d t
$$


Table 2. Main Numerical Models Used for Predicting Noise Around Airports

\begin{tabular}{|c|c|c|}
\hline Country & Model & URL Web Site \\
\hline \hline Germany & AzB & www.stapelfeldt.de \\
\hline & AzB, LAI & www.datakustik.de \\
\hline & AzB/AzB-L, OAL24 & http://www.woelfel.de/wms/noise/index.htm \\
\hline USA & AzB, DIN 45643 & http://www.soundplan.com/introsp.htm \\
\hline Nederland & INM & http://www.aee.faa.gov/Noise/inm/ \\
\hline & RLD/BV01, RLD/BV02 & http://www.rivm.nl/ \\
\hline UK & ANCON 2 & http://www.nlr.nl \\
\hline Australia & TNIP & http://www.dotars.gov.au/aviation/environmental/transparent_noise/tnip.aspx \\
\hline
\end{tabular}

Generally, the admissible level of noise exposure around airports is set by law. At least three different exposition areas are defined: an area with no noise limitations (inside or closest to the airports where no other activity occurs), an area with a medium level of noise protection (industrial or commercial activities), and an area with strict noise limitations (residential areas).

\section{NUMERICAL MODELS FOR AIRCRAFT NOISE PREDICTION}

The first generation of airport noise prediction models were developed without advanced computational resources or measurement instruments [8]. The unreliable observations for model calibration and poor computational resources only allowed for simplified approaches. The first of these was based on the concept of the Closest Point of Approach (CPA) [9]. In this approach, the levels of noise are evaluated assuming a standard noise duration for one single event and the eventual curves of the aircraft trajectories are considered using a numerical post-processing correction. One of the most well-known models under the CPA concept is the German AzB (1975) [7].

More recently, the numerical simulation of noise generation and propagation around airports has allowed for the development of integrated models. These models integrate the evaluation of noise propagation and attenuation with advanced databases containing information about noise level emissions for different aircraft as a function of engine power, aircraft velocity, and the distance between the aircraft and a generic calculation point. These databases are implemented by FAA (Federal Aviation Administration) and aircraft manufacturers. The calculation model in these cases is based on the concept of CPA [10-16].

Later, time-space discretization was introduced into the models. In this process, the aircraft trajectories are discretized into segments and the integration domain is referred to a spatial grid, such as a Digital Elevation Model. Models based on the spatial discretization of the integration domain are generally known as Segmentation Models. Numerical corrections according to the anisotropy of noise emission and attenuations are applied.
The segmentation models are in widespread use because of their short computation time and the availability of an internationally accepted database of NPD-data. The original NPD-database from the FAA (USA) was updated in collaboration with EUROCONTROL to become the "Aircraft Noise and Performance (ANP) database, which is accessible by internet. Other examples of segmentation models are INM (USA) [17, 18], ANCON (UK) [19], DANSIM (DK), Mithra (FR) [20], TNIP (AU) [21], and NORTIM (N).

The revised DOC.29, published in 2004 by ECAC (European Civil Aviation Conference), also recommends a segmentation approach [10].

Simulation models break the flight path down into a series of discrete points. For each point, the geometry from the source to the receiver is clearly defined. The calculation task is reduced to a standard acoustics problem. If required, cross sections of the terrain may be calculated and various sound propagation models may be used to account for wind, temperature, ground effects, and barriers. The sound level at the receiver can be calculated, provided the information about the sound emission from the source and the appropriate directional information is available. This requires a three dimensional, spectral characterization of sound power for the aircraft in-flight conditions at a specified engine power setting.

Each consecutive position on the flight path produces a unique sound level at the receiver. When these levels are lined up, the time history of the sound level is reconstructed (or simulated) and is comparable to measured level-time histories.

There exist variations on how to select the source positions on the flight path. For time step models, the spacing equals the distance flown in one time increment, e.g. one second. Examples of time step models are FLULA $(\mathrm{CH})$ [15], the standard model used in Switzerland with an independent directivity database, NMSIM (USA), an extension of a segment model to short segments, and NORGARD (N) used at airport Gardemoen (Oslo) with locally measured directivity data. Table 2 shows the main numerical models used for predicting noise around airports. 
Table 3. Noise Emission Peak Levels in Standard Conditions for Different Aircraft During Taking Off at a Distance of 1000 Feet

\begin{tabular}{|c|c|c|}
\hline Aircraft & SEL [dB A] & Peak Level [dB A] \\
\hline \hline 707, DC-8 & 113.5 & 104.4 \\
\hline 727 & 112.5 & 106.5 \\
\hline 737, DC-9 & 110.0 & 96.3 \\
\hline 747 & 102.5 & 91.5 \\
\hline 757 & 97.0 & 91.2 \\
\hline 767 & 96.7 & 92.3 \\
\hline DC-10, L-1011 & 100.0 & 89.4 \\
\hline Learjet & 97.1 & 9 \\
\hline
\end{tabular}

\section{A NEW LOW-COST AND EFFECTIVE MODEL: ELENA}

The numerical model for noise level prediction around airports, ELeNA (Evaluation of Level of Noise around Airports), has been developed at the Department of Sciences of Civil Engineering (University Roma Tre, Italy). The model has been developed and implemented with the overall objective of assessing the noise impact of the increasing number of low-cost flights around secondary airports with relatively small financial and human resource requirements.

ELeNA is a segmentation model. The noise level is calculated based on a regular spatial grid. The calculation grid can be superimposed precisely onto the Digital Elevation Model.

The trajectory of the aircraft is discretized in a regular, three dimensional grid that is superimposed on the DEM. The dimension of the single cell of the grid depends on the requested accuracy of the predictions, and it varies from $10 \mathrm{x}$ $10 \mathrm{~m}^{2}$ (for high accuracy) to $500 \times 500 \mathrm{~m}^{2}$ (for preliminary evaluation).

\subsection{Main Variables}

\subsubsection{Noise Generation}

The noise emission from aircraft is simulated as a concentrated noise source. The noise peak level ( $\left.\mathrm{L}_{\mathrm{em} \text { Max }}[\mathrm{dB}]\right)$ is set based on aircraft manufacturer databases. It is basically a function of engine and aerodynamic effects, so it depends on engine power and aircraft speed. Table 3 shows the peak levels assumed for different aircrafts. No frequency spectrum is assumed for the noise source.

\subsubsection{Effects of Aircraft Power and Speed on Noise Generation}

The noise generated by the aircraft is a combination of aerodynamic and mechanical noise. The mechanical noise depends on the power of the engine and it is greater during take-off than landing. Consequently, the model assumes two different peak levels: one for landing and one for take-off. The emitted mechanical noise during take-off is about $30 \%$ greater than that emitted during landing for an aircraft at the same velocity. Aerodynamic noise depends on the aircraft speed. Assuming the value of the aircraft speed for each

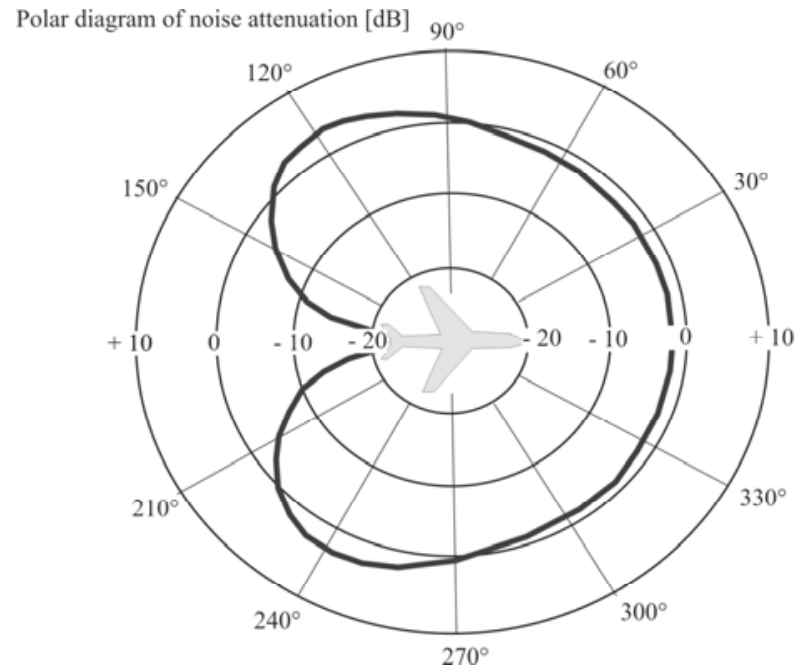

Fig. (2). Polar diagram for evaluation of directional attenuation.

segment of the trajectory is known, ELeNA calculates the attenuation of the emitted noise during each time step with respect to the maximum level of noise at the maximum speed.

$\Delta \mathrm{L}_{v}=\Delta \mathrm{L}_{v \max }+\mathrm{k}_{v}\left(1.0-v / v_{\max }\right)$

where $\quad \mathrm{L}_{\mathrm{w}}(v)=\mathrm{L}_{\mathrm{em} \mathrm{Max}}-\Delta \mathrm{L}_{v}$

$\Delta \mathrm{L}_{v}[\mathrm{~dB}]$ is the noise attenuation as a function of the aircraft speed $v[\mathrm{~km} / \mathrm{h}]$ and the aircraft speed at which the emitted noise is at its maximum $v_{\max } . \mathrm{k}_{v}$ is an attenuation coefficient that has to be calibrated, and $\Delta \mathrm{L}_{v \max }$ is the attenuation level at $v_{\max }$.

\subsubsection{Directional Attenuation of Noise}

Aircraft noise is not emitted isotropically. Fig. (2) shows a diagram of the directional attenuation of the noise. Analogous directional attenuation models have been used in the literature and other databases. The model calculates the angle of directional attenuation for each cell of the grid (calculation point) and for each segment of the trajectory of the aircraft (source position). 


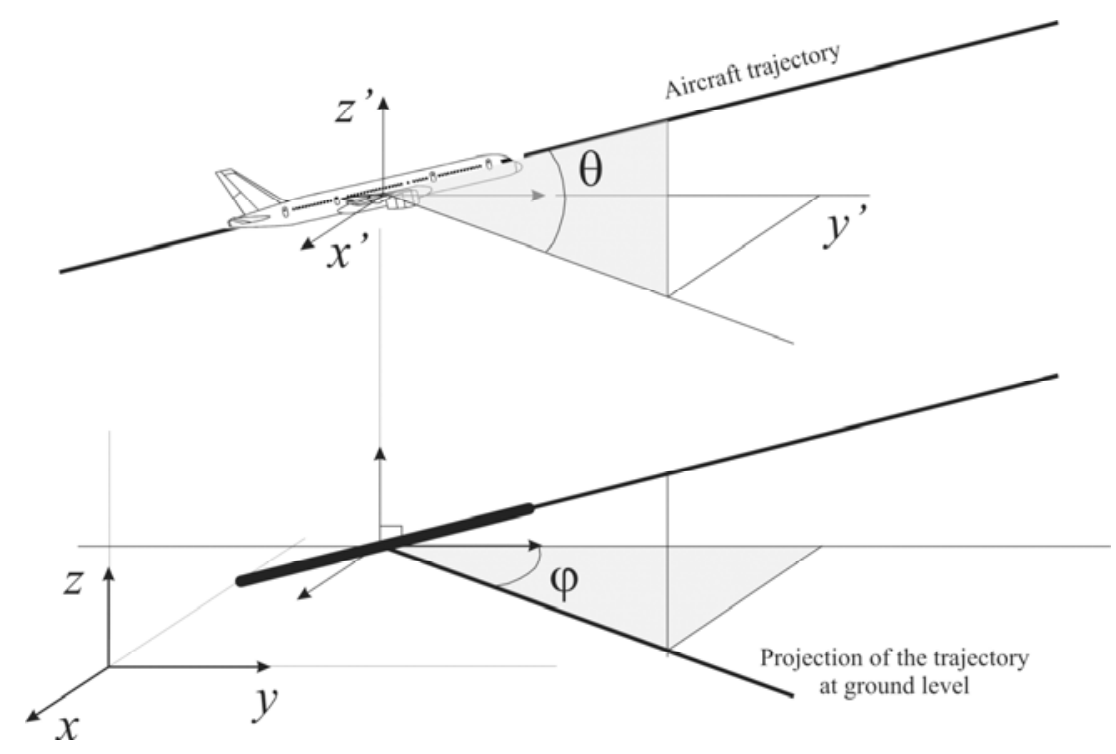

Fig. (3). Geometric scheme for the calculation of directional noise attenuation.

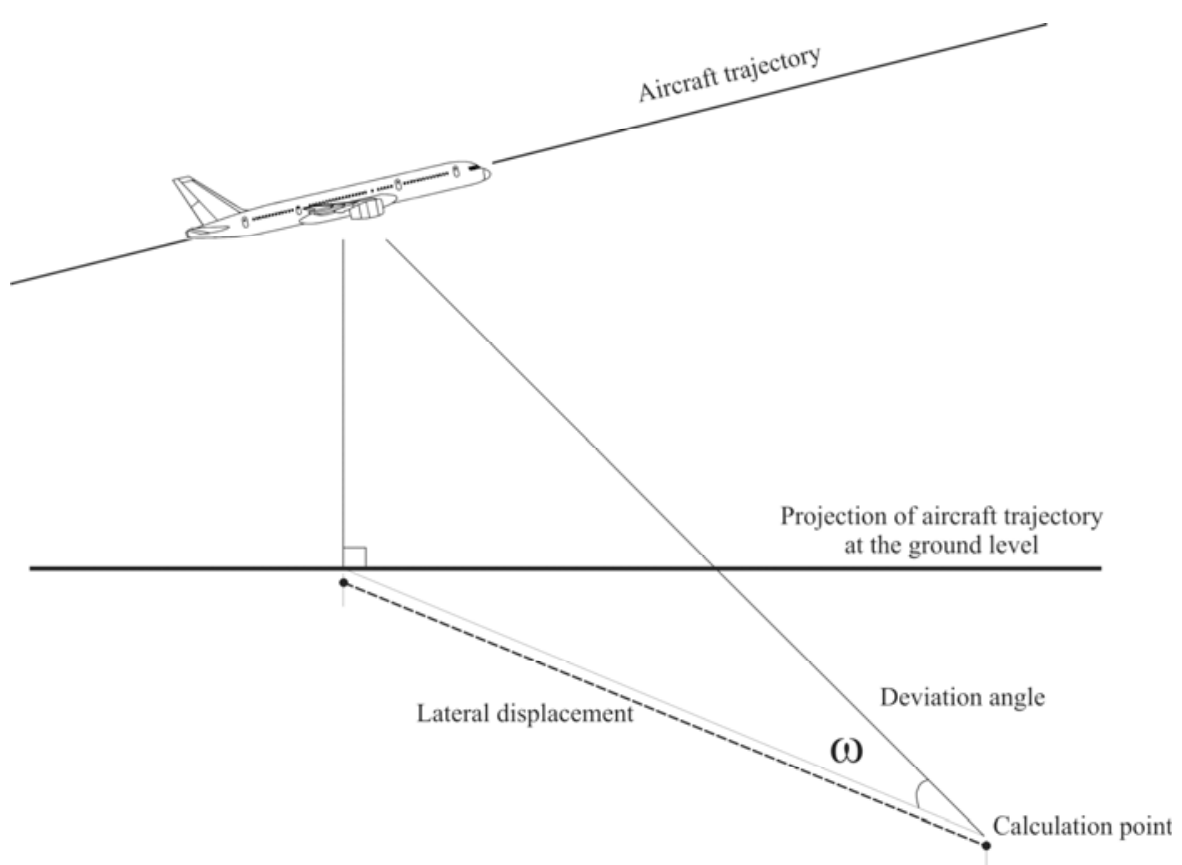

Fig. (4). Geometric scheme for the evaluation of the angle and displacement.

For each cell and for each segment of the trajectory, the angles $\varphi$ and $\theta$ are calculated following the geometric scheme in Fig. (3).

The directional noise attenuation effects are evaluated using the following equation, where $\Delta \mathrm{L}_{\varphi, \theta}$ in $[\mathrm{dB}]$ is the value of attenuation (from Fig. 2):

$\mathrm{L}_{\mathrm{w}}(v)=\mathrm{L}_{\mathrm{em} \mathrm{Max}}-\Delta \mathrm{L}_{\varphi, \theta}$

\subsubsection{Attenuation of Noise from Ground Effects}

Even if the distance from the noise source and the directional attenuation is the same, the noise impact on a given cell at the ground level can be different because of different soil effects. Reflection and noise dispersion depend on the position of the aircraft with respect to the ground. Of course, during the over flight phase, the reflections and noise dispersion effects are very low. In contrast, when the aircraft flies low above the horizon, the ground effects increase greatly.

This is considered calculating the elevation angle $(\omega)$ and the lateral displacement $(d)$ for each cell of the calculation grid for each trajectory segment. Fig. (4) shows the geometric scheme for the evaluation of the angle and displacement. Fig. (5) shows the attenuation of noise from soil effects as a function of the lateral displacement and the elevation angle. These attenuation curves have been generated from databases and the literature. 


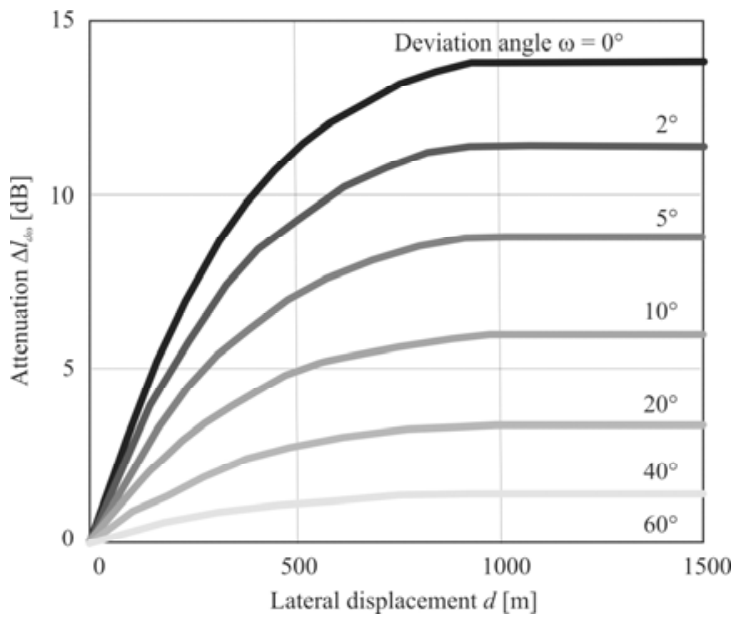

Fig. (5). Attenuation of noise by soil effects as a function of lateral displacement and elevation angle.

The attenuation of noise from ground effects $\left(\Delta \mathrm{L}_{d_{\omega}}\right.$ in $[\mathrm{dB}])$ is evaluated using the following equation

$\mathrm{L}_{\mathrm{w}}(v)=\mathrm{L}_{\mathrm{em} \mathrm{Max}}-\Delta \mathrm{L}_{d_{\omega}}$

where $\quad \Delta \mathrm{L}_{d \omega}=\phi_{\omega} \operatorname{Ln}(d)-\delta_{\omega}$

$\phi_{\omega}$ and $\delta_{\omega}$ are parameters calibrated from noise measurements.

\subsubsection{Attenuation of Noise by Aircraft to Target Distance}

Noise energy from a source is propagated in a quasisphere. As the distance from the source $(\rho)$ increases, the energy density decreases because the energy is distributed over a greater spherical area. Moreover, the noise energy decreases because of dispersions in the atmosphere. The attenuation model for this follows, and it has been calibrated from experimental observations:

$\mathrm{L}_{\mathrm{w}}(\rho)=\mathrm{L}_{\mathrm{em} \mathrm{Max}} \cdot f(\rho)$

where $\quad f(\rho)=\alpha /\left(\alpha+\beta \cdot \rho^{e}\right)$

$\alpha, \beta, e$ are calibration constants.

Fig. (6) shows calibration outcomes where observed levels of noise are compared to the attentuation predication curve as a function of the distance from the noise source.

Finally, the level of noise at the point $x, y$ at time $t$ has been calculated as follows:

$\mathrm{L}_{\mathrm{w}}(x, y, t)=\left[\mathrm{L}_{\mathrm{em} \text { Max }}-\Delta \mathrm{L}_{v}(t)-\Delta \mathrm{L}_{\varphi, \theta}(x, y, t)-\Delta \mathrm{L}_{d_{\omega}}(x, y, t)\right] \cdot$

$f[\rho(x, y, t)]$

\subsection{Model Layout}

ELeNA numerical code predicts the level of noise at the ground during aircraft landing or taking off. The input data are described below:

- A Digital Elevation Model of the ground around the airport is extended to the analysis domain where the dimension of the single cell must be chosen to optimize the accuracy of the simulation. As the dimension of the cell increases, the number of the cells and the computational time decreases greatly, but the accuracy decreases as well. This is why it is

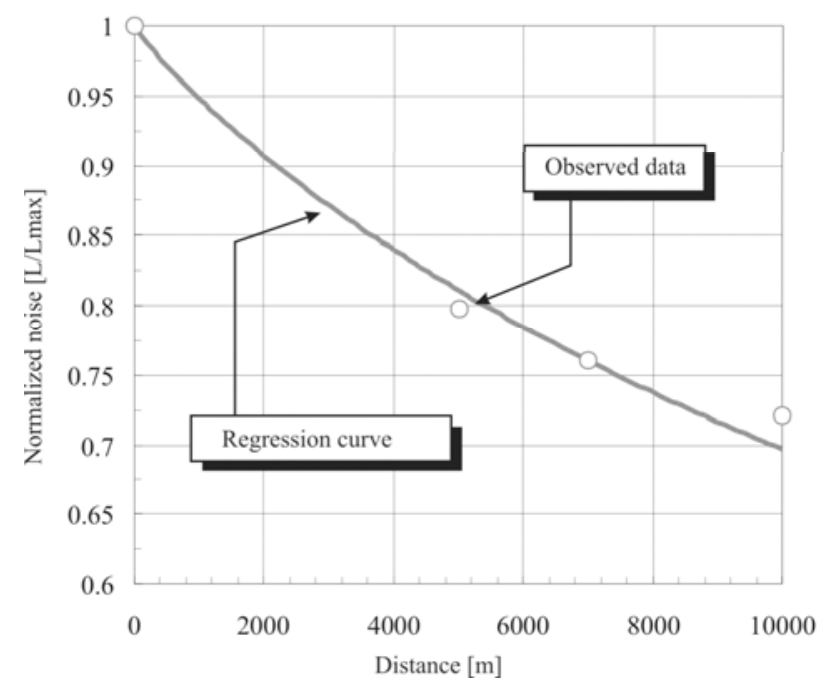

Fig. (6). Example of calibration of the noise source distance attenuation curve.

convenient to calibrate the model using a coarse DEM $\left(100 \times 100 \mathrm{~m}^{2}\right)$ and a fine one $\left(10 \times 10 \mathrm{~m}^{2}\right)$ for the final calculation.

- Aircraft type.

- The flight phase (landing vs. taking off).

- $\quad$ Aircraft trajectory discretized in a Cartesian space the trajectory has to be discretized into segments that align with the dimensions of the DEM being used.

- The angles $\varphi$ and $\theta$ in a polar system between the aircraft longitudinal axis and the Cartesian axes $x$ and $z$, respectively.

- The velocity of the aircraft for each discretized segment of its trajectory.

Starting with these inputs, the numerical code calculates the level of noise in each cell of the DEM for each segment of the aircraft trajectory $(k)$. For each cell $(i)$ of the Digital Elevation Model, the distance $\left(\rho_{i k}\right)$ to the aircraft is computed for each segment $\mathrm{k}$; the elevation angle $\left(\omega_{i k}\right)$ and the trajectory angles $\left(\varphi_{i k}\right.$ e $\left.\theta_{i k}\right)$ are calculated. The attenuation functions are calculated from Eqs. (2), (3), (4), and (5), and the noise level is predicted according to equation (6).

This computation is extended to every trajectory segment, so the noise history is predicted for each DEM cell; consequently, the maximum level of noise during the event is evaluated for each cell.

Fig. (7) shows the model flow chart.

The computation time depends on the DEM dimension and on the length of the aircraft. The computation time generally does not exceed, in a typical study case $\left(10^{4}\right.$ cells and $10^{2}$ trajectories segments), six to eight hours on a commercial PC.

\subsection{Model Calibration}

The ELeNA algorithm has been calibrated using simulation results from other standard codes and validated using on-site measurements. 


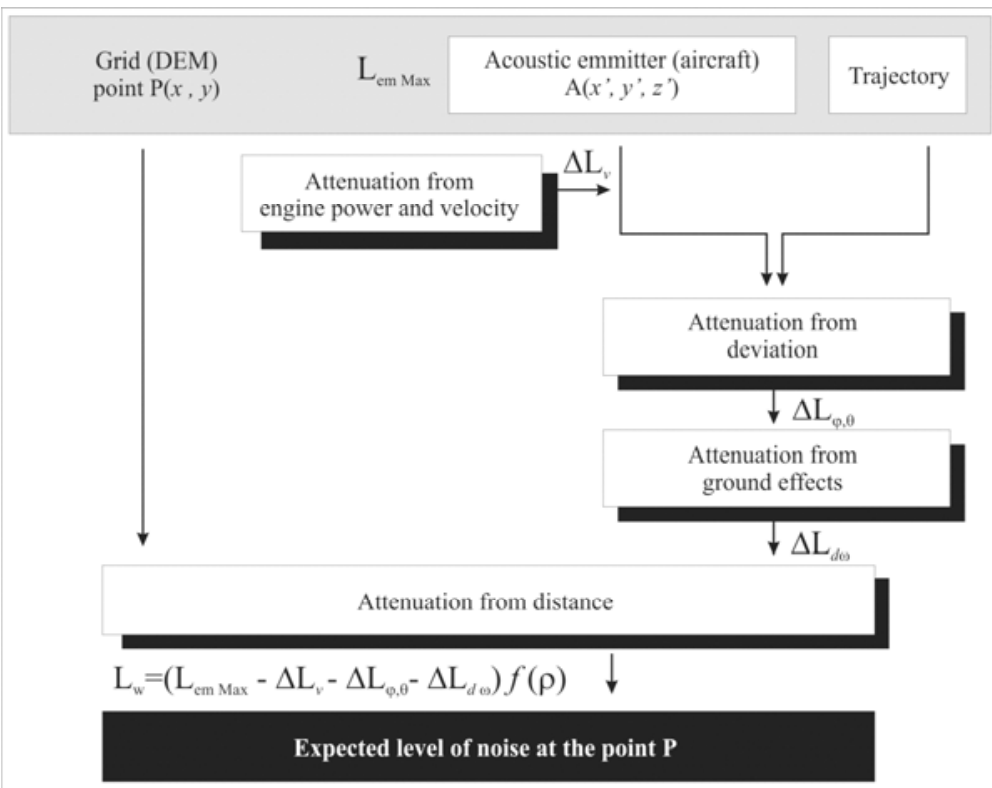

Fig. (7). ELeNA flow chart.

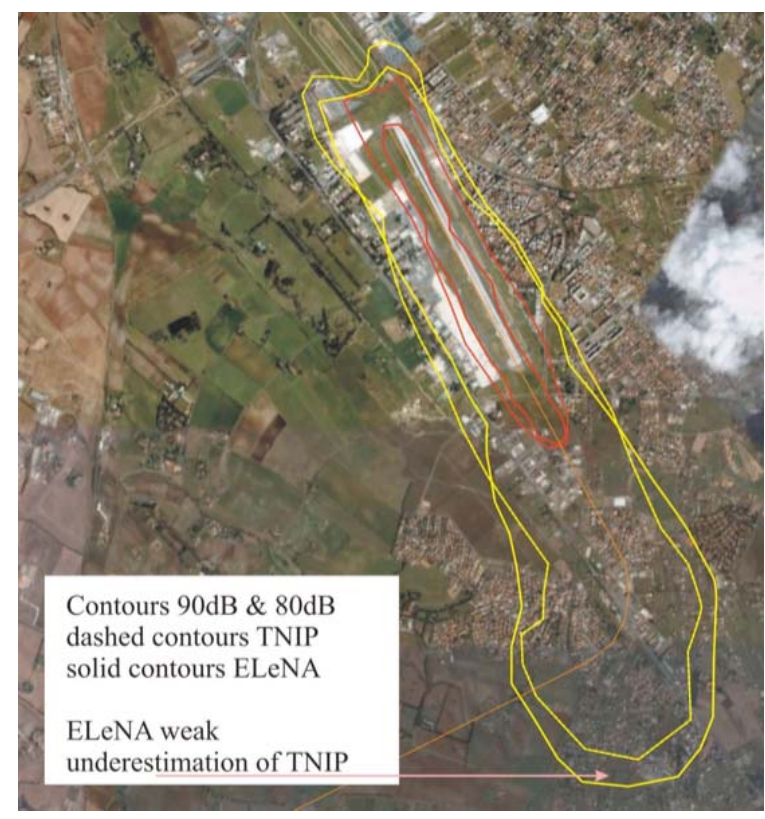

Fig. (8). ELeNA and TNIP predictions for one Lear Jet Taking off.

For ELeNA calibration, two software packages have been considered: the Integrated Noise Model (USA) and the Transparent Noise Package (Australia). The calibration was carried out considering the geometry of the noise contours and the area covered between two contours.

The model parameters assumed for the calibration are:

1. the maximum value of the attenuation of noise dependent on aircraft velocity, $\Delta \mathrm{L}_{v \max }$

2 . the coefficients of the attenuation function based on the distance to the receiver, $\alpha, \beta, e$

3 . the coefficients of the function of the attenuation induced by the elevation of the aircraft from the ground, $\phi_{\omega}$ e $\delta_{\omega}$

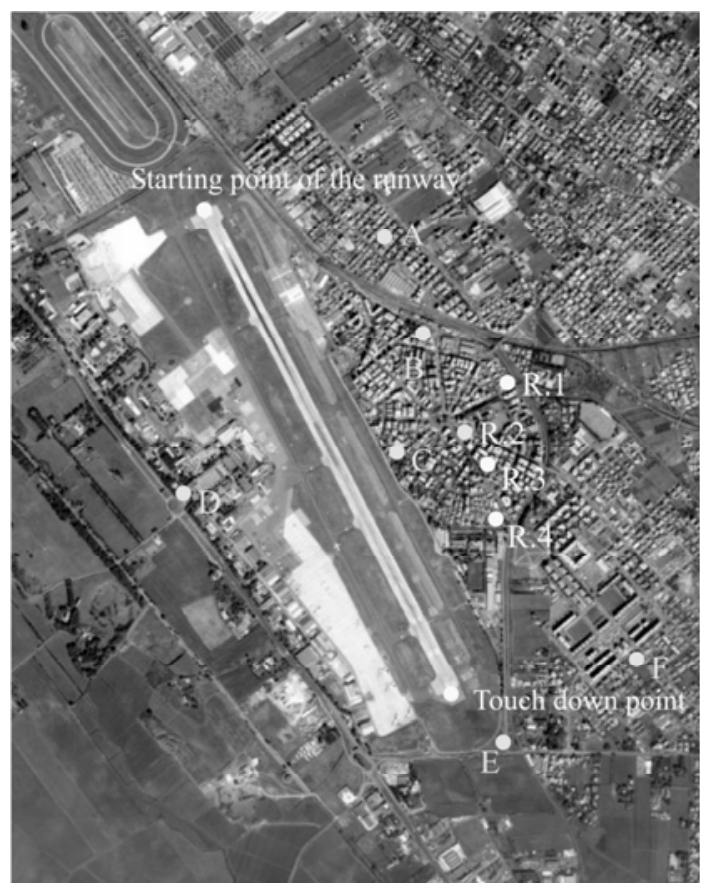

Fig. (9). The position of the measurements site.

The difference between the ELeNA predicted geometry of the noise contours and the geometry predicted by INM and TNIP and the difference between the areas covered between two contours have been minimized by calibrating the above mentioned model parameters.

Fig. (8) shows the ELeNA predictions superimposed on the TNIP prediction for one event: a Lear Jet 35 taking off at the Ciampino airport (Rome, Italy). An analogous comparison has been developed using INM. Good agreement was observed between the various model predictions of the averaged noise levels for one day and one night of flights. port

Fig. (9) shows the measurement points around the air- 


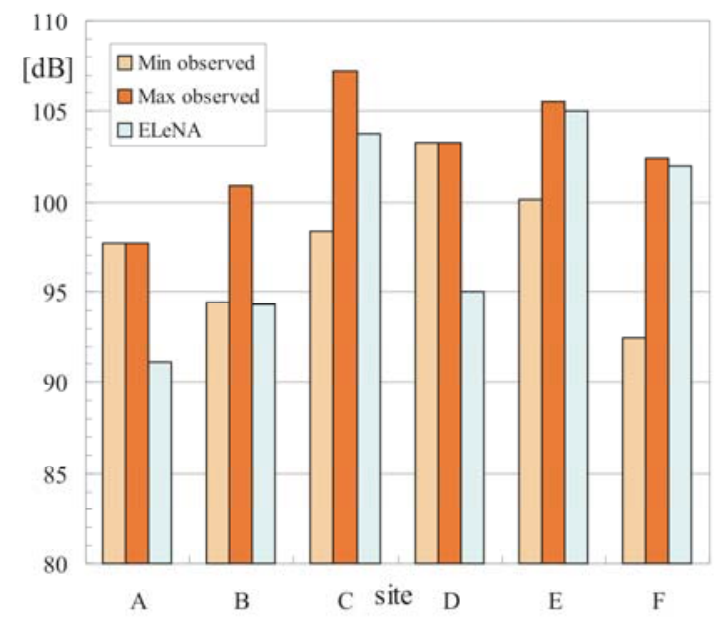

Fig. (10). Comparison between the observed level of noise and ELeNA predictions at some sites.

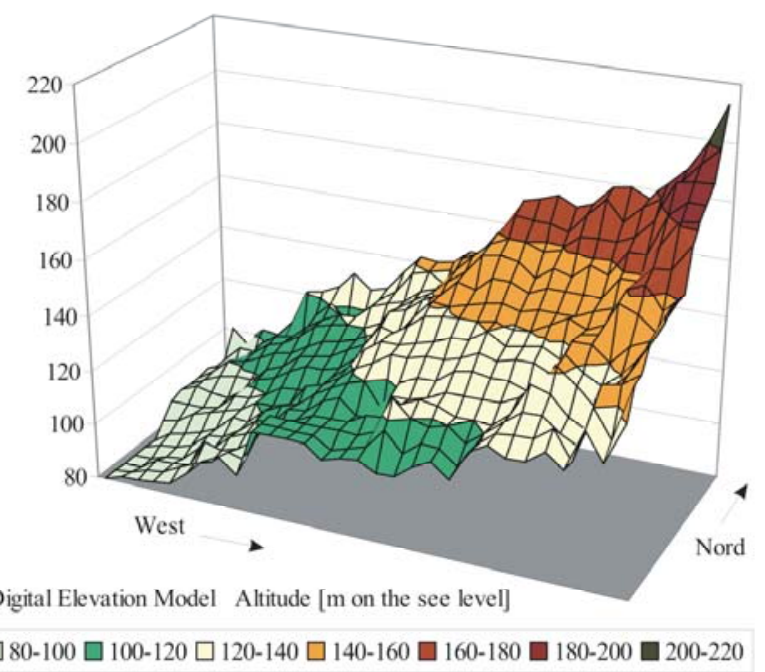

Fig. (11). DEM 250x250 $\mathrm{m}^{2}$ around the Ciampino airport.

Table 4. Increasing of Commercial Air Traffic at Ciampino (Arrivals \& Departures)

\begin{tabular}{|c|c|c|c|c|c|c|}
\hline Year & $\begin{array}{l}\text { Operations } \\
\text { [Number] }\end{array}$ & $\begin{array}{c}\text { Variation } \\
\text { Previous Year [\%] }\end{array}$ & $\begin{array}{l}\text { Passengers } \\
\text { [Number] }\end{array}$ & $\begin{array}{c}\text { Variation } \\
\text { Previous Year [\%] }\end{array}$ & $\begin{array}{l}\text { Cargo } \\
{[\text { Tons] }}\end{array}$ & $\begin{array}{c}\text { Variation Previous } \\
\text { Year [\%] }\end{array}$ \\
\hline 1996 & 18310 & 0.65 & 800525 & 4.21 & 7880 & 6.46 \\
\hline 1997 & 18628 & 1.74 & 864355 & 7.97 & 9783 & 24.15 \\
\hline 1998 & 16366 & -12.14 & 732363 & -15.27 & 10219 & 4.46 \\
\hline 1999 & 17605 & 7.57 & 642525 & -12.27 & 12585 & 23.15 \\
\hline 2001 & 18042 & -8.69 & 692997 & -10.63 & 14854 & 0.79 \\
\hline 2002 & 22315 & 23.68 & 930933 & 34.33 & 18733 & 26.11 \\
\hline 2003 & 30280 & 35.69 & 1765930 & 89.69 & 19781 & 5.59 \\
\hline 2004 & 37036 & 22.31 & 2540854 & 43.88 & 21669 & 9.54 \\
\hline
\end{tabular}

Fig. (10) shows a comparison between noise levels predicted by ELeNA and those observed at points around the Ciampino airport during landing and taking off procedures.

\subsection{The Case of Ciampino Airport (Rome, Italy)}

Here, the case study of the secondary airport in Rome (Italy) is presented.

The Ciampino airport was originally restricted to military and private flights. It is located in an eastern suburb of Rome between the city and the "Castelli Romani" hills.

The town developed around the airport. As a result, residential areas, schools, and a hospital are all close to the runways. This arrangement was compatible with the original low level of air traffic, but the noise and environmental impact is no longer sustainable.

About ten years ago, the airport became very attractive to the low cost carrier, Ryan Air, who increased the number of flights using the airport.
Table 4 shows the increasing air traffic from 1996 to 2005 at Ciampino airport. The number of operations (takeoffs and landings) increased from about 18000 to almost 50000 , but what it is more impressive is that the number of passengers increased from 800 thousand to more than 4 million [22].

The ELeNA model has been implemented to assess the noise impact in the case of the increasing number of operations.

The Digital Elevation Model was developed using cells $25 \times 25 \mathrm{~m}^{2}$. Fig. (11) shows a DEM upscaled to $250 \times 250 \mathrm{~m}^{2}$.

The airport is located in a mostly flat area, but the "Castelli Romani" hills are southeast of the airport and reach a maximum altitude of 990 meters above the sea level. The city of Rome is located to the north and northwest of the airport.

The DEM has been georeferred to allow for accurate location of the aircrafts' trajectories. The trajectories have been 


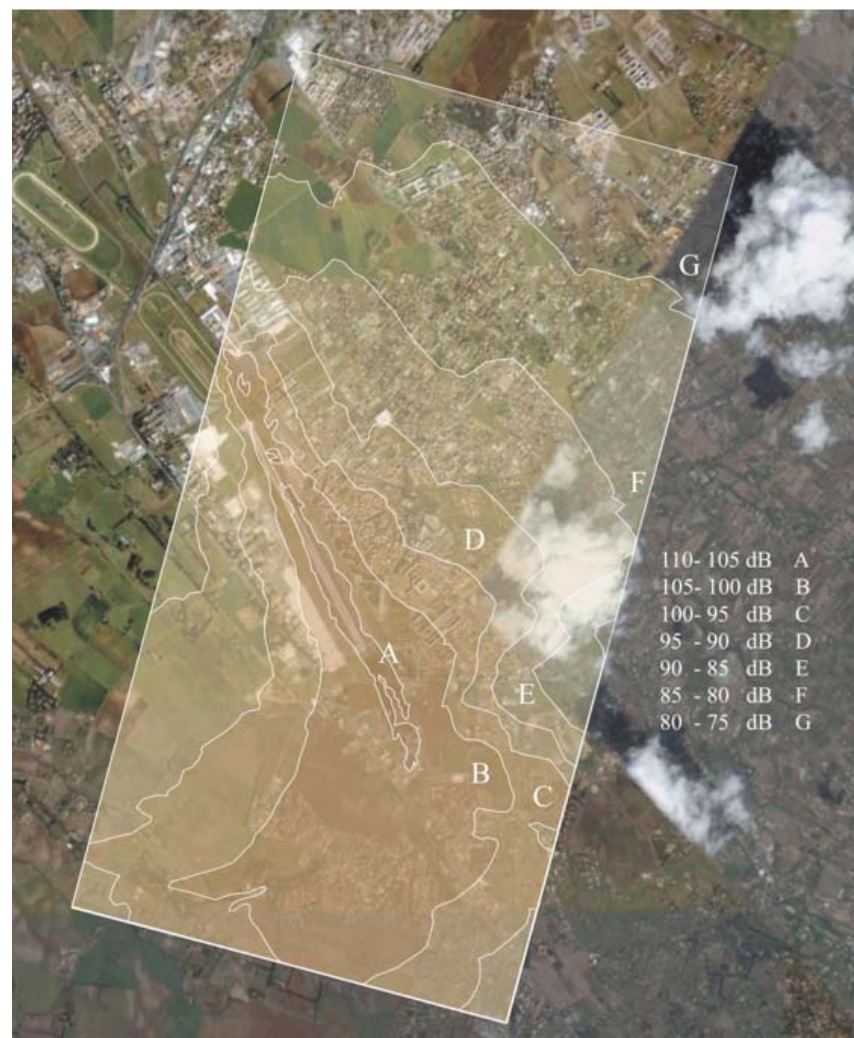

Fig. (12). Noise contours for one Boeing 737 taking off.

discretized from standard ICAO geometries and some on site observations.

Fig. (12) shows one event simulation: the noise level at ground for one Boeing 737 taking off. The contours are obtained from the maximum noise values of the noise histories in each calculation cell.

Of course, using the maximum value of noise, the noise time history is computed over all the cells of the DEM. Fig. (13) shows the noise histories for a few significant points around the airport (runways, schools, hospital).

The model has been used to simulate all the actual operations of taking off and landing to evaluate the average day/night noise. Moreover, it has been used to simulate all the operations that are planned to increase: the planned increase of operations is approximately $15 \%$ of the actual operations. Fig. (14) shows the actual noise contours from taking off; Fig. (15) shows the contours after a $15 \%$ increase in the number of take-offs.

\subsection{Decision Support for Low Cost Terminal Planning (Rome, Italy)}

The actual level of noise around the airport of Ciampino has caused the citizens to protest the proposed increase in noise and traffic. They wanted the regional and local authorities to identify alternative solutions for a third airport linked to Rome for LCCs.

Three candidates were proposed: Viterbo, Frosinone, and Latina. Table 5 summarizes the main characteristics of the three sites.

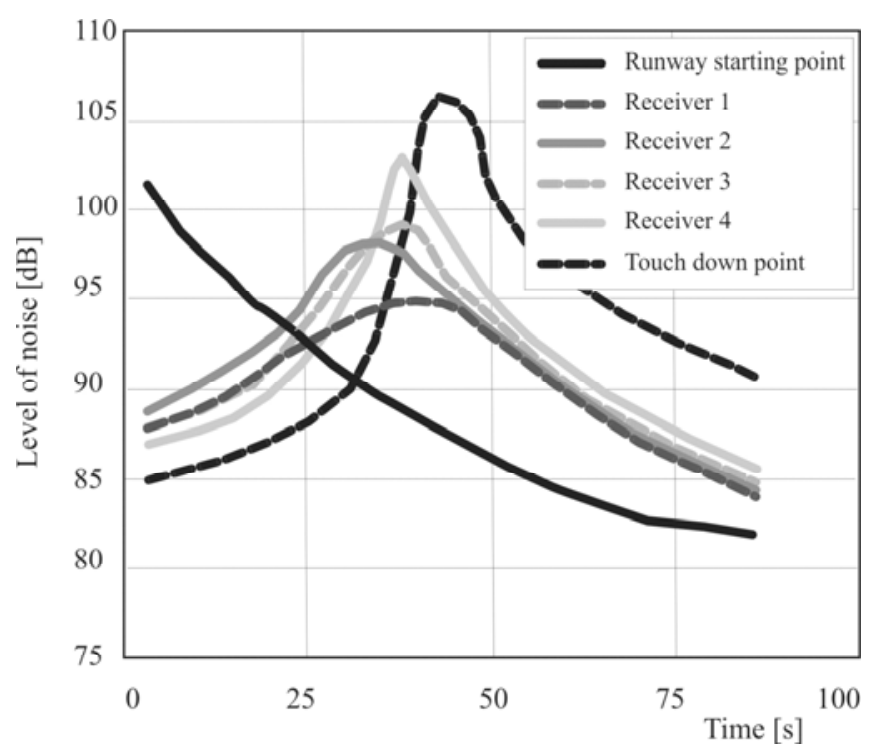

Fig. (13). Noise history for one Boeing 737 take-off at some significant points on the ground.

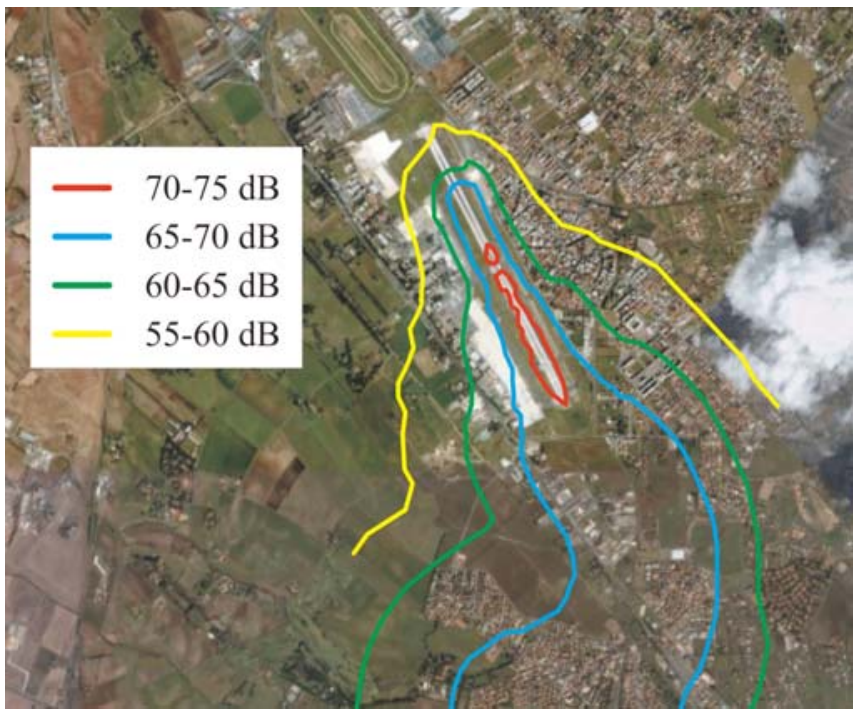

Fig. (14). Noise contours around Ciampino airport from take-off operations in 2006.

The noise impact assessment is generally neglected when planning new airports or rehabilitating existing ones because issues related to aviation safety, land transportation, and economy are priorities. Moreover, the implementation of complex software, such as INM, is not always convenient, both because Environmental Impact Assessment is not requested in many countries of the European Union and abroad (it happens because the airport exists as a secondary terminal and no new infrastructure has been developed in the case of rehabilitated airports) and because the costs of implementation are significant.

ELeNa can be implemented more easily, and it is very efficient and effective at the scale of planning or comparing different locations. 


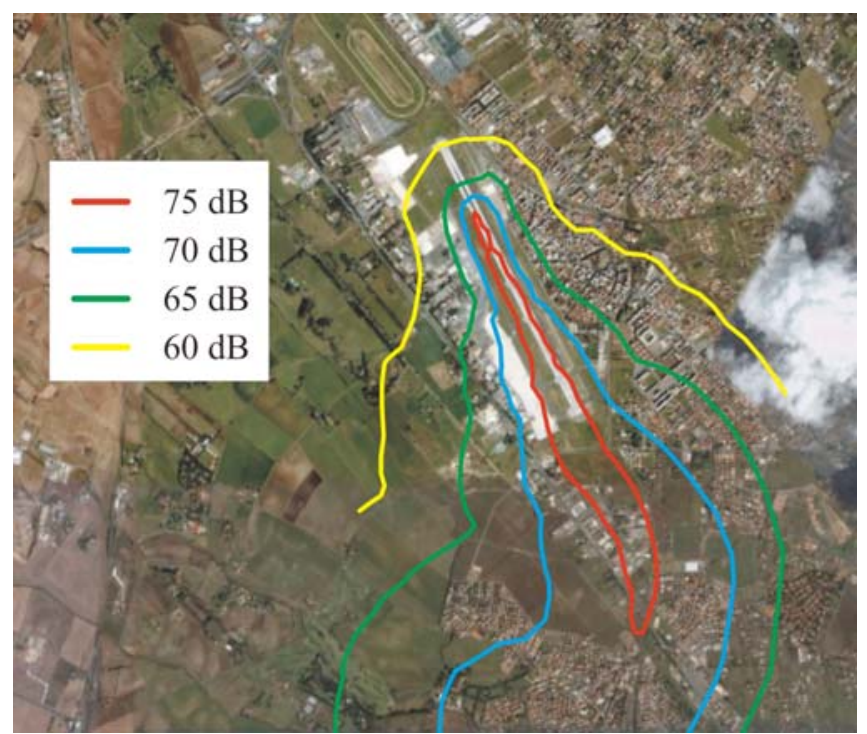

Fig. (15). Noise contours around Ciampino airport from take-off operations in the $2007 / 08$ program $(+15 \%)$.

Table 6 summarizes the outcomes of the simulations. The area and population exposed to different levels of noise evaluated using ELeNA are plotted for the case of one Boeing 737 taking off.
The results demonstrate that, from the acoustic point of view, Latina and Viterbo are the best options. Local and national administrations decided to locate the third terminal at Viterbo because the expected noise impact is compatible with this site.

In summary, ELeNA seems to be very effective as a decision support system both during the evaluation of the noise impact of increasing operations in an existing airport and for the assessment of noise impact in the planning phase for new airports.

\section{CONCLUSIONS}

The application of the proposed numerical model (ELeNA) demonstrates the model's strength as a Decision Support System for evaluating the noise impact around airports both in the case of an increase in the number of flights at an existing airport and in the case of planning a new airport.

The points of strength are: (1) the model is user friendly, (2) the predictions are consistent with the predictions of most advanced models, such as INM or TNIP, (3) the accuracy of predictions is good if the dimension of the cells of the grid is 10 to $10^{2}$ meters, and (4) the computational time and costs are negligible compared to those of INM or TNIP.

Similar to previous algorithms, the ELeNA model is an advanced segmentation model and it takes into account all the main attenuations according to the literature.

Table 5. Main Characteristics of the Three Sites for Low Cost Terminal Localization

\begin{tabular}{|c|c|c|c|}
\hline & Frosinone & Latina & Viterbo \\
\hline \hline Population [inhabitants] & 48600 & 112900 & 60300 \\
\hline Distance to/from Rome by road [km] & 91 & 100 & 118 \\
\hline Time distance to/from Rome by road [min] & 65 & 81 & 86 \\
\hline Time distance to/from Rome by railway [min] & 50 & 28 & 92 \\
\hline Passengers / day by railway & 49000 & 31000 & 70000 \\
\hline Number of trains from Rome /day & 34 & 34 & 30 \\
\hline
\end{tabular}

Table 6. Area and Population Exposed to Different Levels of Noise Evaluated from ELeNA

\begin{tabular}{|c|c|c|c|c|c|c|}
\hline $\begin{array}{l}\text { Noise Level } \\
\qquad[\mathrm{dB}]\end{array}$ & $\begin{array}{c}\text { Frosinone } \\
\text { Exposed Population }\end{array}$ & $\begin{array}{l}\text { Cumulative Exp. } \\
\text { Pop. }\end{array}$ & $\begin{array}{c}\text { Latina } \\
\text { Exposed Population }\end{array}$ & $\begin{array}{l}\text { Cumulative Exp. } \\
\text { Pop. }\end{array}$ & $\begin{array}{c}\text { Viterbo } \\
\text { Exposed Population }\end{array}$ & $\begin{array}{l}\text { Cumulative Exp. } \\
\text { Pop. }\end{array}$ \\
\hline $55-60$ & 259 & 259 & 23 & 23 & 44 & 44 \\
\hline $60-65$ & 496 & 755 & 94 & 117 & 59 & 104 \\
\hline $65-70$ & 662 & 1417 & 202 & 319 & 74 & 178 \\
\hline $70-75$ & 372 & 1789 & 94 & 413 & 222 & 400 \\
\hline $75-80$ & 2420 & 4208 & 258 & 671 & 311 & 712 \\
\hline $80-85$ & 1293 & 5501 & 141 & 812 & 326 & 1038 \\
\hline $85-90$ & 3578 & 9079 & 155 & 967 & 311 & 1350 \\
\hline $90-95$ & 2647 & 11726 & 70 & 1037 & 163 & 1513 \\
\hline $95-100$ & 1903 & 13628 & 190 & 1227 & 98 & 1611 \\
\hline $100-105$ & 2378 & 16006 & 329 & 1556 & 122 & 1732 \\
\hline
\end{tabular}




\section{REFERENCES}

[1] F. Evangelo, C. Huse, and A.Linhares, "Market entry of a low cost airline and impacts on the Brazilian business travelers", Journal of Air Transport Management, vol. 11, pp. 99-105, 2005.

[2] R. Doganis, The Airline Business in the 21st Century. Routledge, London, 2001.

[3] C. Barbot, "Low-cost airlines, secondary airports, and state aid: an economic assessment of the Ryanair-Charleroi Airport agreement", Journal of Air Transport Management, vol. 12, pp. 197-203, 2006.

[4] K.J. Mason, "The propensity of business travellers to use low cost airlines", Journal of Transport Geography, vol. 8, pp. 107-119, 2000.

[5] D. Gillen, and W. Morrison, "Bundling, integration and the delivered price of air travel: are low cost carriers full service competitors?" Journal of Air Transport Management, vol. 9, pp. 15-23, 2003.

[6] P. Forsyth, "Airport competition and the efficiency of price structures at major airports", GARS Research Seminar, Leipzig, 2003.

[7] AZB, "Der Bundesminister des Innern: bekanntmachung der Datenerfassungssysteme für die Ermittlung von Lärmschutzbereichen an zivilen (DES) und militärischen Flugplätzen (DESMIL) sowie einer Anleitung zur Berechnung" (AZB). Gem. Ministerialblatt 26, Ausgabe A, Nr. 8,126-227, Bonn, 10. März 1975.

[8] N. J. S. Burton, "Methods of assessment of aircraft noise". London South Bank University, Department of Engineering Systems, MSc in Environmental and Architectural Acoustics, London, UK, 2004.

[9] F. Högkvarteret, "Swedish aircraft noise calculation model", CAA Revision 4, Luftfartsverket, 2003.

[10] ICAO "International civil aviation organization recommended method for computing noise contours around airports", Circular 205-AN/1/25, 1988.

[11] ECAC. CEAC Doc.29, European Civil Aviation Conference on Standard Method of Computing Noise Contours around Civil Airports, 1986.
[12] P. Morrell, "Airlines within airlines: an analysis of US network airline responses to Low Cost Carriers", Journal of Air Transport Management, vol. 11, pp. 303-312, 2005.

[13] SAE AIR 1845 Society of Automotive Engineers, "Procedure for the aircraft noise in the vicinity of airports", 1986.

[14] SAE AIR 1751 "Prediction method of lateral attenuation of airplane noise during takeoff and landing", Note: reaffirmed 1991, 1981

[15] S.J. Pietrzko, and R.F. Hofmann, "FLULA prediction of AWeighted aircraft noise based on measured directivity patterns", Journal of Applied Acoustics, vol. 23, pp. 29-44, 1988.

[16] O. I. Zaporozhets, and V. I. Tokarev, "Aircraft noise modelling for environmental assessment around airports", Applied Acoustics, vol 55(2), pp. 99-127, 1998

[17] J.M. Olmstead, G.G. Fleming, and J.R. Gulding, "INM 6 user guide: integrated noise model (INM) version 6.0 users guide", Department of Transportation, Federal Aviation Administration, Report No. FAA-AEE-99-03, 1999.

[18] J.M. Olmstead, G.G. Fleming, and J.R. Gulding, "INM 6 technical guide: integrated noise model (INM) version 6.0 technical manual", Department of Transportation, Federal Aviation Administration, Report No. FAA-AEE-02-01, 2002.

[19] J.B. Ollerhead, D.P. Rhodes, M.S. Viinikainen, D.J. Monkman, and A.C. Woodley, "The UK aircraft noise contour model ANCON: improvements in version 2", CAA ERCD Report 9842, June 1996.

[20] Mithra 5.0 "Manuel de l'utilisateur, 01dB-Stell ; Mithra-Avion 4.02, additif au manuel de l'utilisateur, fonctionnalités spécifiques à Mithra-Avion", CSTB-DGAC, Novembre 2000.

[21] TNIP "Expert, from australian government", Department of Transport and Regional Services, Version 1.0, May 2005.

[22] ENAC "Ripartizione del mercato aereo italiano tra compagnie Low Cost e Tradizionali", Andamento del traffico nei singoli aeroporti italiani. Annuario Statistico 2005.

(c) Andrea Benedetto; Licensee Bentham Open.

This is an open access article licensed under the terms of the Creative Commons Attribution Non-Commercial License (http://creativecommons.org/licenses/by-nc/3.0/) which permits unrestricted, non-commercial use, distribution and reproduction in any medium, provided the work is properly cited. 